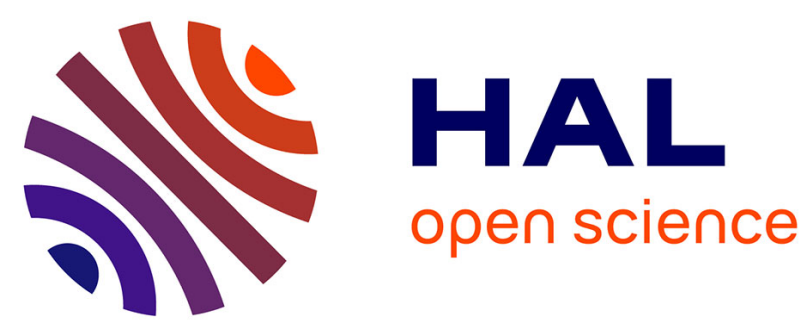

\title{
Paramagnetic Properties of a Crystalline Iron-Sulfur Protein by Magic-Angle Spinning NMR Spectroscopy
}

\author{
Andrea Bertarello, Tobias Schubeis, Carmelo Fuccio, Enrico Ravera, Marco
}

Fragai, Giacomo Parigi, Lyndon Emsley, Guido Pintacuda, Claudio Luchinat

\section{- To cite this version:}

Andrea Bertarello, Tobias Schubeis, Carmelo Fuccio, Enrico Ravera, Marco Fragai, et al.. Paramagnetic Properties of a Crystalline Iron-Sulfur Protein by Magic-Angle Spinning NMR Spectroscopy. Inorganic Chemistry, 2017, 10.1021/acs.inorgchem.7b00674 . hal-01546469

\section{HAL Id: hal-01546469 \\ https://hal.science/hal-01546469}

Submitted on 27 Apr 2018

HAL is a multi-disciplinary open access archive for the deposit and dissemination of scientific research documents, whether they are published or not. The documents may come from teaching and research institutions in France or abroad, or from public or private research centers.
L'archive ouverte pluridisciplinaire HAL, est destinée au dépôt et à la diffusion de documents scientifiques de niveau recherche, publiés ou non, émanant des établissements d'enseignement et de recherche français ou étrangers, des laboratoires publics ou privés. 


\title{
Paramagnetic Properties of a Crystalline Iron-Sulfur Protein by Magic- Angle Spinning NMR Spectroscopy
}

\author{
Andrea Bertarello, ${ }^{1 \ddagger}$ Tobias Schubeis, ${ }^{1,2 \ddagger}$ Carmelo Fuccio, ${ }^{3}$ Enrico Ravera, ${ }^{3}$ Marco Fragai, ${ }^{3,4}$ \\ Giacomo Parigi, ${ }^{3,4}$ Lyndon Emsley, ${ }^{5}$ Guido Pintacuda, ${ }^{1,{ }^{*}}$ Claudio Luchinat ${ }^{2,3,4^{*}}$
}

1. Centre de RMN à Très Hauts Champs, Institut des Sciences Analytiques (CNRS, ENS Lyon, UCB Lyon 1), Université de Lyon, 69100 Villeurbanne, France, 2. Giotto Biotech S.R.L., Via Madonna del Piano 6, 50019 Sesto Fiorentino, Italy, 3. Magnetic Resonance Center (CERM) and Interuniversity Consortium for Magnetic Resonance of Metallo Proteins (CIRMMP), Via L. Sacconi 6, 50019 Sesto Fiorentino, Italy, 4. Department of Chemistry "Ugo Schiff", University of Florence, Via della Lastruccia 3, 50019 Sesto Fiorentino, Italy, 5. Institut des Sciences et Ingénierie Chimiques, Ecole Polytechnique Fédérale de Lausanne (EPFL), CH-1015 Lausanne, Switzerland.

ABSTRACT: We present the first solid-state NMR study of an iron-sulfur protein. The combined use of very fast $(60 \mathrm{kHz})$ magic-angle spinning (MAS) and tailored RF irradiation schemes allows the detection and the assignment of most of the ${ }^{1} \mathrm{H}$ and ${ }^{13} \mathrm{C}$ resonances of the oxidized highpotential iron-sulfur protein I from E. halophila (EhHiPIP I), including those in residues coordinating the $\mathrm{Fe}_{4} \mathrm{~S}_{4}$ cluster. For these residues, contact shifts as large as $100 \mathrm{ppm}$ and $400 \mathrm{ppm}$ for ${ }^{1} \mathrm{H}$ and ${ }^{13} \mathrm{C}$ resonances, respectively, were observed, which represent the most shifted solidstate NMR signals ever measured in metalloproteins. Interestingly, by targeting EhHiPIP I in a crystalline environment, we were able to capture distinct paramagnetic signatures from the two conformations present in the asymmetric unit. The magnetic properties of the system were verified by following the temperature dependence of the contact-shifted cysteine resonances.

\section{Introduction}

A vast share of the whole proteome of all living organisms is made by metalloproteins: metal ions play an important role in a large variety of biochemical and cellular events, and many of them contain unpaired electrons which make them paramagnetic. ${ }^{1}$ The presence of such paramagnetic metal centers induces large modifications on the magnetic properties of the surrounding nuclei, and it has long been proven that the measurement of such effects by NMR provides a direct access to the electronic structure and the underlying molecular geometries and thus chemical properties of metalloproteins. $^{2}$

However, not all the paramagnetic metalloproteins are amenable for solution NMR characterization, mostly because of molecular size or aggregation state, which make the NMR signals broad beyond detection. Building on a decade of methodological and technical advancements, magic-angle spinning (MAS) NMR has emerged as a new tool for the characterization of biomolecular samples. ${ }^{3}$ This technique has experienced a real revolution with the introduction of very fast (>30 kHz) MAS probes. ${ }^{4}$ In this new spinning regime, sensitivity and 
resolution experience a spectacular enhancement as compared to slower rates. Thanks to these developments, it has already been shown that nuclei in close proximity to a metal center can be efficiently detected ${ }^{5}$ and that faster MAS translates into a significant reduction of the blind zone close to the metal center with respect to solution studies. ${ }^{6}$ The most remarkable difference between solution and the solid state is that Curie relaxation, one of the major contributors to paramagnetic line broadening, is absent in the solid state. ${ }^{7}$

However, up to now, only a handful of high-resolution solid-state NMR studies have been performed on paramagnetic metalloproteins. They mainly concerned two enzymes in microcrystalline form, the human superoxide dismutase (SOD) ${ }^{8}$ and the catalytic domain of matrix-metalloproteinase-12 (MMP-12), ${ }^{6}{ }^{9}$ two proteins with high-affinity binding sites for divalent paramagnetic cations such as $\mathrm{Cu}^{2+}$ (SOD) or $\mathrm{Co}^{2+}$ (MMP and SOD). Expanding the repertoire of solid-state NMR accessible paramagnetic systems is however not necessarily a trivial task, because of the different properties of the different metals in the different coordination environments that are encountered in metalloproteins. An example of this is represented by trivalent lanthanide ions, where the quality of the spectra is extremely dependent on the properties of the metal ligands: whereas small inorganic complexes ${ }^{10}$ or rigid binding sites in proteins ${ }^{11}$ yield substantially sharp lines, a more flexible coordination environment reorients the magnetic susceptibility tensor, ${ }^{12}$ producing significant inhomogeneous broadening, or possibly reintroducing Curie relaxation. ${ }^{13}$

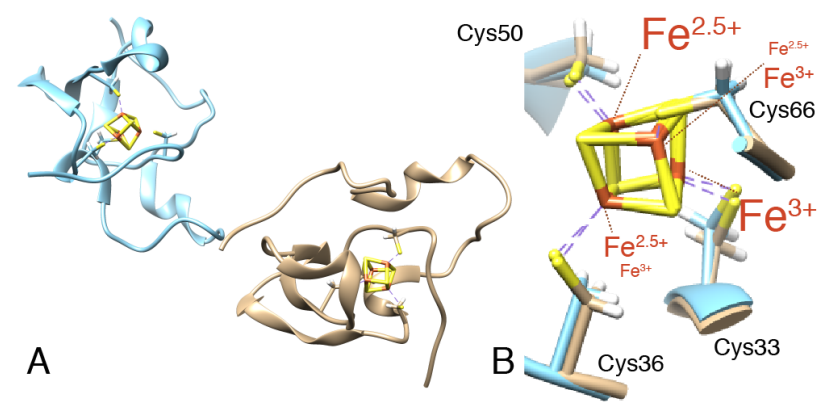

Figure 1. A) Asymmetric unit of EhHiPIP I showing the two molecules. B) Superposition of the two molecules showing the cluster and the coordinating cysteines.

Among the biologically relevant metal ions, iron plays an important role. Pioneering work by the McDermott group has used information from paramagnetic shifts to identify the ligand position in cytP450 adducts, ${ }^{14}$ and more recently Ramamoorthy's group has provided a detailed characterization of membrane bound cytP450 ${ }^{15}$ and described a model of the membrane-bound cytb5-cytP450 complex by the combined use of solution and solid-state NMR. ${ }^{16}$ Here, we report the first solid-state NMR data on a protein containing an iron-sulfur $\mathrm{Fe}_{4}-\mathrm{S}_{4}$ cluster. Iron-sulfur clusters are ubiquitous prosthetic groups of many metalloenzymes, ${ }^{17}$ often associated to membranes, and they have a variety of functions in diverse cellular processes in almost all life- 
forms. ${ }^{1}$ In a first seminal work, solid-state NMR was used to elucidate the fine details of the electronic structure of model $\mathrm{Fe}_{4}-\mathrm{S}_{4}$ cluster compounds by studying the dependence of their isotropic and anisotropic ${ }^{13} \mathrm{C}$ shifts over a very large temperature range. ${ }^{18}$ Here, we use NMR at very fast MAS, together with a set of spectroscopic tools recently developed for the study of highly paramagnetic materials, ${ }^{5 c, 19}$ to characterize the high-potential iron-sulfur protein I from $E$. halophila (EhHiPIP I) ${ }^{20}$ in a microcrystalline preparation. In EhHiPIP I, a cubane $\mathrm{Fe}_{4} \mathrm{~S}_{4}$ cluster is coordinated by the side-chains of four cysteine residues (Cys33, Cys36, Cys50 and Cys66). In its oxidized form, it formally contains one $\mathrm{Fe}^{2+}$ ion and three $\mathrm{Fe}^{3+}$ ions, but experimental data are consistent with the cluster being formed by one mixed valence pair (with $S=9 / 2$ ), containing two $\mathrm{Fe}^{2.5+}$ ions and one ferric ions pair containing two $\mathrm{Fe}^{3+}$ ions (forced by exchange coupling to $S=4$, see later), resulting in an overall spin of the cluster equal to $1 / 2{ }^{20-21}$

Over the last twenty years, EhHiPIP I has become a model system for biophysical applications, and has been extensively characterized by X-ray crystallography, ${ }^{22}$ EPR and Mössbauer measurements at very low temperatures, ${ }^{23}$ Raman spectroscopy, ${ }^{23}$ and solution NMR, ${ }^{21,}{ }^{24}$ where the electronic properties of the $\mathrm{Fe}_{4} \mathrm{~S}_{4}$ cluster give distinctive features in the ${ }^{1} \mathrm{H}^{24-25}$ and ${ }^{13} \mathrm{C}$ spectra. ${ }^{21}$ The electronic properties of $\mathrm{Fe}_{4} \mathrm{~S}_{4}$ clusters are made extremely complex by the presence of the highly asymmetric protein matrix that induces equilibria between different charge distributions among the iron ions. In particular, EhHiPIP I has two EPR isomers: while one iron is always $2.5+$ and another is always $3+$, two other irons exchange $2.5+$ and $3+$ character with $80 \%$ / $20 \%$ probability (Figure 1B). ${ }^{20}$ This is actually rather common among the different HiPIPs (see Figure 6 in reference ${ }^{20}$ ). The mixed valence pair usually assumes the higher spin state (thus the corresponding shifts are positive) and forces the ferric pair to have a lower spin state with opposed spin, due to exchange coupling, yielding as mentioned above a ground state of the type $|9 / 2,4,1 / 2\rangle$. To further complicate the picture, it is found that the ground state is not a pure $|9 / 2,4,1 / 2\rangle$ state, but rather a superposition of different states. ${ }^{26}$ However, since the behavior of HiPIPs has remarkable similarities, one can expect the exchange coupling parameters to be similar to what has been estimated with a quantum mechanical formalism for EhHiPIP II, which has a single EPR isomer. ${ }^{27}$

Besides benchmarking MAS-NMR with a new target paramagnetic system, the present investigation on microcrystalline EhHiPIP I thus represents an important complement to the literature data, by providing a link between the characterizations of the molecule in solutions and in crystals. Most notably here, the unit cell of crystalline EhHiPIP I contains two molecules, featuring an overall backbone RMSD of $0.67 \AA$ (Figure 1 ). ${ }^{22}$ Considering that paramagnetic NMR shifts are highly sensitive to the local geometry, ${ }^{28}$ solid-state NMR could be able to capture distinct signatures from the two conformations present in the asymmetric unit. 


\section{Experimental Section}

Protein preparation. Purified ${ }^{13} \mathrm{C},{ }^{15} \mathrm{~N}$ labeled HiPIP I from E. halophila was purchased from Giotto Biotech S.r.l. (Sesto Fiorentino, Italy). Protein solutions of $10 \mathrm{mg} / \mathrm{ml}$ were dialysed against $10 \mathrm{mM}$ TRIS pH 8. Protein crystals were grown by sitting drop vapor diffusion using a ratio of 1:1 (protein / reservoir). The reservoir solution consisted of 3.5 M Ammonium Sulfate, $100 \mathrm{mM}$ MES $\mathrm{pH}$ 5.6. Platelet-like crystals were obtained in 3-4 days. Crystals were harvested by centrifugation and packed in a $1.3 \mathrm{~mm}$ rotor using the ultracentrifugal device 1 (Bruker Biospin). ${ }^{29}$ The rotor was center-packed with FKM inserts (courtesy of Bruker Biospin) to avoid dehydration.

NMR experiments. Paramagnetic solid-state NMR experiments were performed on a $500 \mathrm{MHz}$ Bruker Avance III spectrometer equipped with a double-resonance $1.3 \mathrm{~mm}$ probe. All experiments were acquired at $60 \mathrm{kHz}$ MAS. The temperature was regulated in order to obtain an estimated sample temperature of $298 \mathrm{~K}$, unless otherwise specified. One dimensional ${ }^{1} \mathrm{H}$ spectra were acquired with the double adiabatic spin echo sequence using tanh/tan refocusing pulses at $200 \mathrm{kHz}$, with a sweep width of $500 \mathrm{kHz}$ over 50 us. ${ }^{7,} 19$ The water signal was suppressed by presaturation using a continuous pulse of $2 \mathrm{kHz}$ for $10 \mathrm{~ms}$. The recycle delay was set to $20 \mathrm{~ms}$. The ${ }^{1} \mathrm{H}-{ }^{1} \mathrm{H}$ radiofrequency driven recoupling (RFDR) spectrum ${ }^{30}$ was acquired using a mixing time of $0.5 \mathrm{~ms}$, a recycle delay of $20 \mathrm{~ms} .{ }^{31}$ The $\left({ }^{1} \mathrm{H}\right)-{ }^{13} \mathrm{C}$ transferred echo double resonance (TEDOR) ${ }^{32}$ was acquired with a recoupling period of $16.67 \mu$ s (one rotor period) and a recycle delay of 50 ms. A two-dimensional adiabatic magic-angle turning (aMAT) experiment ${ }^{33}$ was used to estimate the shift anisotropies of each individual signal in the spectrum. This experiment was acquired using a non-selective 90 pulse, six tanh/tan SHAPs that swept through $5 \mathrm{MHz}$ in $50 \mu \mathrm{s}$, and a recycle delay of $50 \mathrm{~ms}$. Experiments for backbone assignments $(2 \mathrm{D}(\mathrm{H}) \mathrm{NH}, 3 \mathrm{D}(\mathrm{H}) \mathrm{CANH}$, $(\mathrm{H})(\mathrm{CO}) \mathrm{CA}(\mathrm{CO}) \mathrm{NH},(\mathrm{H}) \mathrm{CONH}$ and $(\mathrm{H}) \mathrm{CO}(\mathrm{CA}) \mathrm{NH})^{34}$ were recorded on a $1 \mathrm{GHz}$ Bruker Avance III spectrometer equipped with a triple-resonance $1.3 \mathrm{~mm}$ probe at $60 \mathrm{kHz}$ MAS. For each of these correlations, the experimental parameters are listed in Table S1.

\section{Results and discussion}

Figure $2 \mathrm{~A}$ shows the ${ }^{1} \mathrm{H},{ }^{15} \mathrm{~N}$ dipolar-based correlation spectrum of oxidized EhHiPIP I obtained on a $1 \mathrm{GHz}$ spectrometer at a MAS rate of $60 \mathrm{kHz}$.

This spectrum correlates the frequency of each amide ${ }^{1} \mathrm{H}$ with that of its bonded ${ }^{15} \mathrm{~N}$ spin, and thus provides a fingerprint of the protein, similar to the ${ }^{1} \mathrm{H},{ }^{15} \mathrm{~N}$ scalar-based correlation acquired in solution. ${ }^{34-35}$ Using a recently established approach, sequence-specific assignments of these resonances were obtained with the help of $3 \mathrm{D}$ spectra, correlating ${ }^{1} \mathrm{H},{ }^{15} \mathrm{~N}$ to the neighboring ${ }^{13} \mathrm{CO} /{ }^{13} \mathrm{CA}$, either in the same or in the previous residue. The set of four 3D spectra was jointly analyzed, so to simultaneously match the two independent ${ }^{13} \mathrm{C}$ (CO and CA) chemical shifts that are correlated with ${ }^{1} \mathrm{H}$ and ${ }^{15} \mathrm{~N}$ nuclei from adjacent residues (Figure S1).

This procedure allowed for a partial assignment of the backbone resonances, which reveals the presence of two distinct $\mathrm{HN}$ peaks for several residues. Differences up to $0.5 \mathrm{ppm}$ in the ${ }^{1} \mathrm{H}$ 
dimension were observed (e.g. for His12, Arg26 and GIn28 as displayed in Figure 2A), compatible with the two backbone conformations observed by X-ray.

Figure $2 \mathrm{~B}$ and $2 \mathrm{C}$ display the $1 \mathrm{D}{ }^{1} \mathrm{H}$ and ${ }^{13} \mathrm{C}$ spectra of oxidized EhHiPIP I, obtained on a $500 \mathrm{MHz}$ spectrometer at a MAS rate of $60 \mathrm{kHz}$. These two spectra contain contact shifted resonances, up to $100 \mathrm{ppm}$ in the ${ }^{1} \mathrm{H}$ case and up to $400 \mathrm{ppm}$ for ${ }^{13} \mathrm{C}$, associated to the nuclei in $\beta$ and $\alpha$ positions in the cysteine residues coordinating the $\mathrm{Fe}_{4} \mathrm{~S}_{4}$ cluster. To our knowledge, these resonances represent the most hyperfine-shifted signals observed for a metalloprotein by solid-state NMR. In both cases, a double spin-echo with two adiabatic pulses (short high-powered adiabatic pulses, SHAPs) ${ }^{19}$ was employed to achieve broadband excitation without phase distortions. The interpretation of these spectra was made easier by the acquisition of two additional 2D maps, a ${ }^{1} \mathrm{H}-{ }^{1} \mathrm{H}$ RFDR spectrum (Figure 2D), ${ }^{30}$ which correlates protons close in space, and a $\left({ }^{1} \mathrm{H}\right)-{ }^{13} \mathrm{C}$ TEDOR spectrum, ${ }^{32}$ which correlates pairs of nearby protons and carbons (Figure $2 \mathrm{E}$ ).

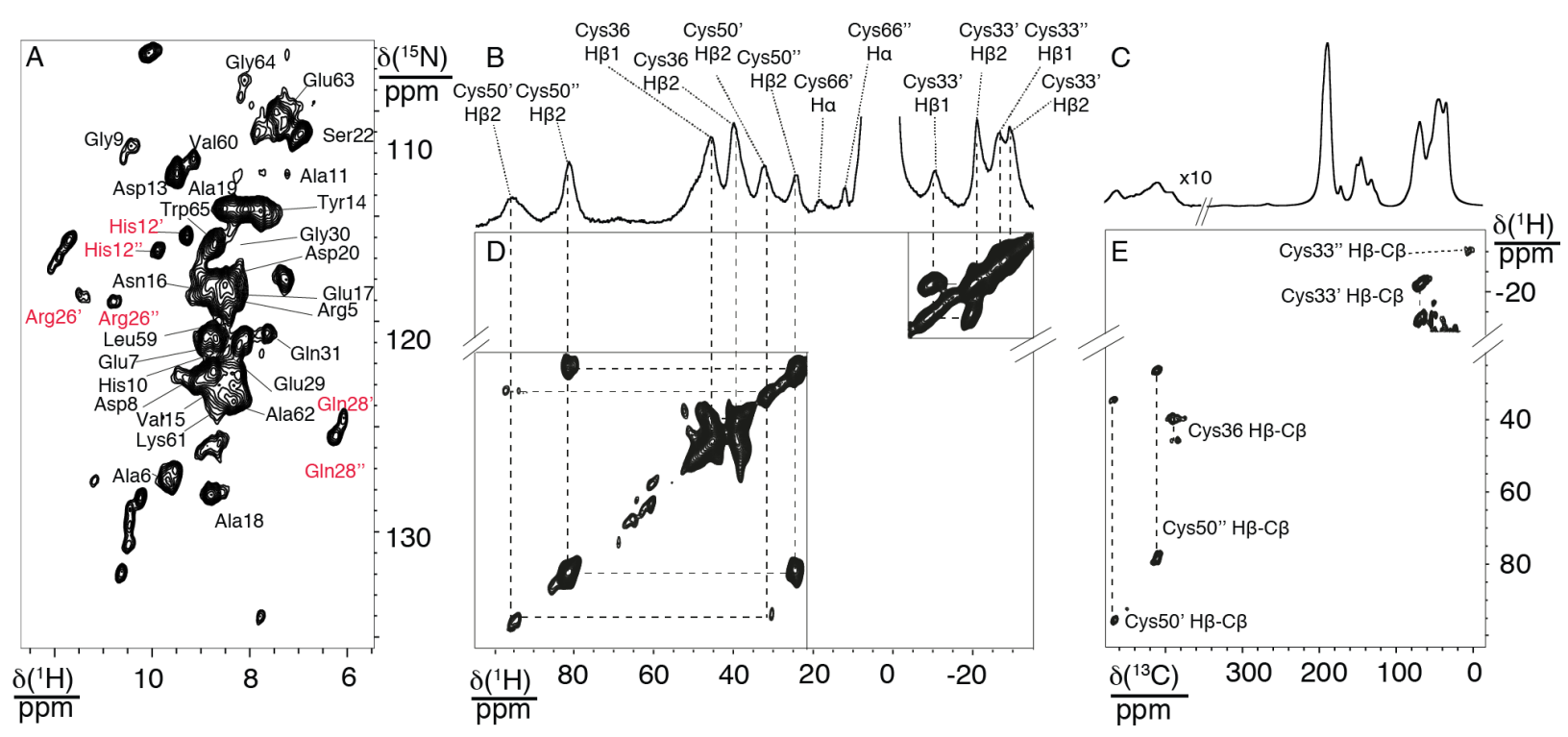

Figure 2. A) $1 \mathrm{H}, 15 \mathrm{~N}$ correlation spectrum of EhHiPIP I. B) $1 \mathrm{H}$ and C) $13 \mathrm{C}$ double-adiabatic echo spectrum. D) Selected regions of the $1 H-1 H$ RDFR spectrum. E) Selected regions of the (1H)-13C TEDOR spectrum. (') and (") denote the two different forms observed for that residue.

Note that the short relaxation times of these strongly paramagnetic signals and their large isotropic chemical shifts obliterate spin diffusion and prevent heteronuclear coherence transfers by cross-polarization, while the pulsed methods used here provide a broadband, offsetinsensitive route to efficient 2D correlations. ${ }^{5 c}$ The hyperfine-shifted peaks show very limited dipolar (or contact) shielding anisotropy (Fig. S2). This, coupled with the small size of the protein, explains the limited contribution of Curie-spin relaxation in this system in solution. The pattern of the ${ }^{1} \mathrm{H}$ and ${ }^{13} \mathrm{C}$ contact-shifted resonances is characteristic of the electronic distribution in the oxidized $\mathrm{Fe}_{4} \mathrm{~S}_{4}$ cluster, and is analogous to what already reported in solution (see Table S2). ${ }^{20-21,25}$ 
As mentioned above, based on the distribution of the hyperfine shift values of the protons of the coordinating cysteines, it was proposed that Cys50 coordinates the iron which is always mixed valence, Cys33 coordinates the iron which is always ferric, and the oxidation of the iron ions bound to the other two cysteines undergoes an exchange between two states with $80 \% / 20 \%$ population: ${ }^{21}$ Cys36 is mainly mixed, and Cys66 is mainly ferric. The two pairs are antiferromagnetically coupled to each other, and the mixed valence pair dominates the pattern. ${ }^{20}$, ${ }^{36}$ The iron ion in the mixed-valence state induces a strong downfield shift on the coordinating cysteine proton and carbons signals (Cys50). The Fe ion in the ferric state induces an upfield shift on the protons and carbons of the attached cysteine (Cys33). The ion with large (80\%) ferric character induces a small downfield shift on the coordinating cysteine signals (Cys66), while the one with transient (20\%) ferric character induces a downfield shift on the attached cysteine (Cys36) which is smaller than that induced by a $100 \%$ mixed-valence. Interestingly, it is apparent that for three cysteines out of four, the contact-shifted resonances show a doubling in the MAS NMR spectra of crystalline EhHiPIP I as compared to the solution case, however the pattern is clearly maintained, allowing for direct porting of the solution assignment (see below), in turn allowing for assignment of the bound carbons appearing in the TEDOR spectrum. Similarly, in the $2 \mathrm{D}$ maps of Figure $2 \mathrm{D}$ and $2 \mathrm{E}$, the correlation patterns expected on the basis of the solution NMR shifts are doubled. In particular, it appears that two forms are observable for Cys50 and Cys33, for which each $\mathrm{H} \beta$ and $\mathrm{C} \beta$ nucleus displays two different chemical shift values. Different from the case of the $\mathrm{HN}$ correlations, here the chemical shift difference between equivalent signals is more than 10 ppm. Only one set of resonances is observable for Cys36, but the considerable broadening of these two peaks suggests that two species with very close chemical shift values may be associated to this residue as well. For Cys66 $\mathrm{H} \beta$ and $\mathrm{C} \beta$ are not observable, being buried in the diamagnetic region of the spectrum, but from the $\mathrm{H} \alpha$ and $\mathrm{C} \alpha$ resonances it is clear that this residue features two forms as well.

${ }^{1} \mathrm{H}$ and ${ }^{13} \mathrm{C}$ chemical shifts and their assignment are reported in Table S2. It is interesting to observe how in all the cases the chemical shift values in solution are very close to the average of the values observed in the solid state. This may indicate that the conformation of the clustercoordinating cysteines in solution is intermediate or exchanges between two extreme conformations represented by the two different molecules found in the crystal.

The possibility to detect strongly contact shifted ${ }^{1} \mathrm{H}$ signals in microcrystalline EhHIPIP I allows for the measurement of their temperature dependence, which in turn is a direct reporter of the magnetic properties of the system. Under MAS, the temperature dependence of the proton chemical shifts could be probed in the range between $293 \mathrm{~K}$ and $305 \mathrm{~K}$. Figure 3 shows the Curie plot obtained from these measurements, and linearly-fitted slopes and intercepts are reported in the SI. Cys50 and Cys36 H $\beta$ resonances, which are both bound to a mostly mixed-valence Fe ion, follow a Curie-like temperature dependence, while Cys33 $\mathrm{H} \beta$ resonances, bound to a Fe ion belonging to the ferric pair, follow a hyper-Curie dependence ${ }^{37}$ (also termed pseudo-Curie in the 
case of coupled metals), extrapolating quite far downfield in the limit of infinite temperature. Cys66 Ha resonances follow instead an anti-Curie behavior, extrapolating far downfield at infinite temperature too (for a discussion of the terms hyper-Curie, pseudo-Curie and anti-Curie see refs. $\left.{ }^{36-38}\right)$. The data reveal that a similar behavior is generally observed in solution and in the solid state, and that no appreciable differences between the trends of the two sets of resonances associated to the two different forms can be observed in the solid state. This confirms that the spin distributions of the iron ions are preserved in the solid state, and the model used to interpret solution data can thus be still considered valid. This is particularly useful to confirm the performed assignment, especially where the little difference in chemical shifts makes it difficult to discriminate between $\mathrm{H} \beta 1$ and $\mathrm{H} \beta 2$ protons, as in the case of Cys33. Interestingly, the curves of Cys50 and Cys33 in solution have somewhat different slopes from those observed in the solid state for the two forms. This may suggest that on changing temperature a modest structural change could occur in solution, in such a way that the conformation passes from being closer to one to being closer to the other of the two forms present in the solid state.

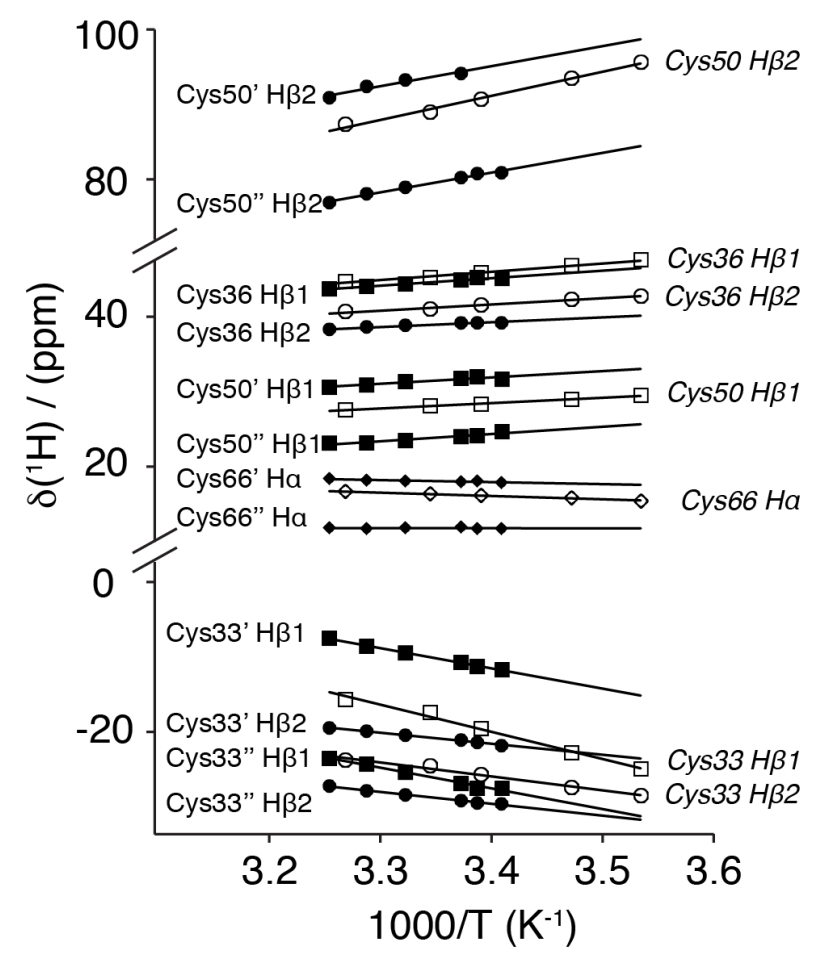

Figure 3. Curie plot of EhHiPIP I in solution 25 (empty symbols) and in the solid state (full symbols).

\section{Conclusions}

In summary, we showed that solid-state NMR with very fast MAS rates and tailored RF irradiation schemes allows for the complete characterization of a highly paramagnetic metalloprotein containing an oxidized Fe-S cluster in a microcrystalline state. Notably, resolved resonances from nuclei that experience considerable ${ }^{1} \mathrm{H}$ and ${ }^{13} \mathrm{C}$ hyperfine shifts were detected 
and assigned to two inequivalent conformations of the cubane cluster present in the asymmetric unit. The magnetic properties of the system were finally verified by following the variable temperature changes of the contact shifts. Fe-S clusters are common in biochemistry and are present in many membrane-bound systems, which cannot be easily accessed by atomicresolution diffraction techniques. We expect therefore that the methods described above will be very broadly applicable to such important class of targets. The recent advances in MAS technology (>100 kHz), combined with the forthcoming developments in very high field technology, are expected to ease even more the access to backbone as well as sidechain assignments and collection of restraints, because of improved resolution in proton detection in fully-protonated samples. ${ }^{39}$ We foresee that this will also prompt new methodological developments for observing hyperfine shifted resonances. ${ }^{40}$

\section{ACKNOWLEDGEMENTS}

This research was supported by the CNRS (IR-RMN FR3050), the Fondazione Cassa di Risparmio di Firenze, the MIUR PRIN 2012SK7ASN, the People Programme of the European Union's FP7 (FP7-PEOPLE-2012-ITN n³17127 “pNMR”), the European Research Council (ERC) under the European Union's Horizon 2020 research and innovation programme (grant n648974 "P-MEM-NMR"), the European Commission projects BioMedBridges No. 284209, iNEXT No. 653706, and Instruct, part of the European Strategy Forum on Research Infrastructures (ESFRI). Specifically, we thank the EU ESFRI Instruct Core Centre CERM, Italy. ER holds a FIRC triennial fellowship “Gino Mazzega and Guglielmina Locatello" (17941).

\section{REFERENCES}

(1) Handbook on metalloproteins; Bertini, I., Sigel, A., Sigel, H., Eds.; Marcel Dekker, Inc.: New York, 2001.

(2) Bertini, I.; Luchinat, C.; Parigi, G.; Ravera, E. NMR of Paramagnetic Molecules. Applications to Metallobiomolecules and Models; Elsevier: Boston, 2017.

(3) Recent achievements and new directions in biomolecular solid state NMR. J. Magn. Reson. 2015, 253, (Tycko, R. ed.)

(4) Knight, M. J.; Felli, I. C.; Pierattelli, R.; Emsley, L.; Pintacuda, G. Magic angle spinning NMR of paramagnetic proteins. Acc. Chem. Res. 2013, 46, 2108-2116.

(5) (a) Ishii, Y.; Wickramasinghe, N. P.; Chimon, S. A new approach in 1D and 2D C-13 high-resolution solid-state NMR spectroscopy of paramagnetic organometallic complexes by very fast magic-angle spinning. J. Am. Chem. Soc. 2003, 125, 3438-3439; (b) Wickramasinghe, N. P.; Shaibat, M.; Ishii, Y. Enhanced sensitivity and resolution in H-1 solid-state NMR spectroscopy of paramagnetic complexes under very fast magic angle spinning. J. Am. Chem. Soc. 2005, 127, 5796-5797; (c) Kervern, G.; Pintacuda, G.; Zhang, Y.; Oldfield, E.; Roukoss, C.; Kuntz, E.; Herdtweck, E.; Basset, J. M.; Cadars, S.; Lesage, A.; Coperet, C.; Emsley, L. Solid-state NMR of a paramagnetic DIAD-Fe-II catalyst: Sensitivity, resolution enhancement, and structure-based assignments. J. Am. Chem. Soc. 2006, $128,13545-13552$.

(6) Bertini, I.; Emsley, L.; Lelli, M.; Luchinat, C.; Mao, J.; Pintacuda, G. Ultrafast MAS Solid-State NMR permits extensive $13 \mathrm{C}$ and $1 \mathrm{H}$ detection in paramagnetic metalloproteins. J. Am. Chem. Soc. 2010, 132, 5558-5559.

(7) Kervern, G.; Steuernagel, S.; Engelke, F.; Pintacuda, G.; Emsley, L. Absence of Curie relaxation in paramagnetic solids yields long $\mathrm{H}-1$ coherence lifetimes. J. Am. Chem. Soc. 2007, 129, 14118-14119.

(8) (a) Pintacuda, G.; Giraud, N.; Pierattelli, R.; Böckmann, A.; Bertini, I.; Emsley, L. Solid-State NMR of a paramagnetic protein: assignment and study of the human dimeric oxidized Zn(II)-Cu(II) Superoxide Dismutase (SOD). Angew. Chem. Int. Ed. Eng/ 2006, 46, 1079-1082; (b) Laage, S.; Lesage, A.; Emsley, L.; Bertini, I.; Felli, I. C.; Pierattelli, R.; Pintacuda, G. Transverse-Dephasing Optimized Homonuclear J-Decoupling in Solid-State NMR Spectroscopy of Uniformly C-13-Labeled Proteins. J. Am. Chem. Soc. 2009, 131, 10816-10817; (c) Knight, M. J.; Felli, I. C.; Pierattelli, R.; Bertini, I.; Emsley, L.; Herrmann, T.; Pintacuda, G. Rapid measurement of pseudocontact shifts in metalloproteins by proton-detected solid-state NMR spectroscopy. J. Am. Chem. Soc. 2012, 134, 14730-14733; (d) Knight, M. J.; Pell, A. J.; Bertini, I.; Felli, I. C.; Gonnelli, L.; Pierattelli, R.; Herrmann, T.; Emsley, L.; Pintacuda, G. Structure and backbone dynamics of a microcrystalline metalloprotein by solid-state NMR. Proc. Natl. Acad. Sci. U.S.A. 2012, 109, 11095-11100. 
(9) (a) Balayssac, S.; Bertini, I.; Lelli, M.; Luchinat, C.; Maletta, M. Paramagnetic ions provide structural restraints in solid-state NMR of proteins. J. Am. Chem. Soc. 2007, 129, 2218-2219; (b) Luchinat, C.; Parigi, G.; Ravera, E.; Rinaldelli, M. Solid-State NMR Crystallography through Paramagnetic Restraints. J. Am. Chem. Soc. 2012, 134, 5006-5009.

(10) (a) Huang, W.; Schopfer, M.; Zhang, C.; Howell, R. C.; Todaro, L.; Gee, B. A.; Francesconi, L. C.; Polenova, T. 31P magic angle spinning NMR spectroscopy of paramagnetic rare-earth-substituted Keggin and Wells-Dawson solids. J. Am. Chem. Soc. 2008, 130, 481-490; (b) Kervern, G.; D'Aleo, A.; Toupet, L.; Maury, O.; Emsley, L.; Pintacuda, G. Crystal-structure determination of powdered aramagnetic lanthanide Complexes by proton NMR Spectroscopy. Angew. Chem. Int. Ed. 2009, 48, 3082-3086.

(11) Li, J.; Pilla, K. B.; Li, Q.; Zhang, Z.; Su, X.; Huber, T.; Yang, J. Magic Angle Spinning NMR Structure Determination of Proteins from Pseudocontact Shifts. J. Am. Chem. Soc. 2013, 135, 8294-8303.

(12) Boulon, M.-E.; Cucinotta, G.; Luzon, J.; Degl'Innocenti, C.; Perfetti, M.; Bernot, K.; Calvez, G.; Caneschi, A.; Sessoli, R. Magnetic Anisotropy and Spin-Parity Effect Along the Series of Lanthanide Complexes with DOTA. Angew. Chem. Int. Ed. 2013, 52, 350-354.

(13) Bhaumik, A.; Luchinat, C.; Parigi, G.; Ravera, E.; Rinaldelli, M. NMR crystallography on paramagnetic systems: solved and open issues. CrystEngComm 2013, 15, 8639-8656.

(14) (a) Lee, H.; Ortiz de Montellano, P. R.; McDermott, A. E. Deuterium Magic Angle Spinning Studies of Substrates Bound to Cytochrome P450. Biochemistry 1999, 38, 10808-10813; (b) Jovanovic, T.; McDermott, A. E. Observation of Ligand Binding to Cytochrome P450 BM-3 by Means of Solid-State NMR Spectroscopy. J. Am. Chem. Soc. 2005, 127, 13816-13821.

(15) Yamamoto, K.; Gildenberg, M.; Ahuja, S.; Im, S. C.; Pearcy, P.; Waskell, L.; Ramamoorthy, A. Probing the transmembrane structure and topology of microsomal cytochrome-p450 by solid-state NMR on temperature-resistant bicelles. Sci. Rep. 2013, 3, 2556.

(16) (a) Ahuja, S.; Jahr, N.; Im, S. C.; Vivekanandan, S.; Popovych, N.; Le Clair, S. V.; Huang, R.; Soong, R.; Xu, J.; Yamamoto, K.; Nanga, R. P.; Bridges, A.; Waskell, L.; Ramamoorthy, A. A model of the membrane-bound cytochrome b5-cytochrome P450 complex from NMR and mutagenesis data. J. Biol. Chem. 2013, 288, 22080-95; (b) Yamamoto, K.; Durr, U. H.; Xu, J.; Im, S. C.; Waskell, L.; Ramamoorthy, A. Dynamic interaction between membrane-bound full-length cytochrome P450 and cytochrome b5 observed by solid-state NMR spectroscopy. Sci. Rep. 2013, 3, 2538.

(17) (a) Brancaccio, D.; Gallo, A.; Mikolajczyk, M.; Zovo, K.; Palumaa, P.; Novellino, E.; Piccioli, M.; Ciofi-Baffoni, S.; Banci, L. Formation of [4Fe-4S] clusters in the mitochondrial iron-sulfur cluster assembly machinery. J. Am. Chem. Soc. 2014, 136, 16240-16250; (b) Banci, L.; Brancaccio, D.; Ciofi-Baffoni, S.; Del Conte, R.; Gadepalli, R.; Mikolajczyk, M.; Neri, S.; Piccioli, M.; Winkelmann, J. [2Fe-2S] cluster transfer in iron-sulfur protein biogenesis. Proc. Natl. Acad. Sci. USA 2014, 111, 6203-8; (c) Cai, K.; Tonelli, M.; Frederick, R. O.; Markley, J. L. Human Mitochondrial Ferredoxin 1 (FDX1) and Ferredoxin 2 (FDX2) Both Bind Cysteine Desulfurase and Donate Electrons for Iron-Sulfur Cluster Biosynthesis. Biochemistry 2017, 56, 487-499.

(18) Crozet, M.; Chaussade, M.; Bardet, M.; Emsley, L.; Lamotte, B.; Mouesca, J.-M. Carbon-13 Solid-State NMR Studies on Synthetic Model Compounds of [4Fe-4S] Clusters in the 2+ State. J. Phys. Chem. A 2000, 104, 9990-10000.

(19) Kervern, G.; Pintacuda, G.; Emsley, L. Fast adiabatic pulses for solid-state nmr of paramagnetic systems. Chem. Phys. Lett. 2007, 435, 157-162.

(20) Bertini, I.; Capozzi, F.; Eltis, L. D.; Felli, I. C.; Luchinat, C.; Piccioli, M. Sequence-specific assignment of ligand cysteine protons of oxidized, recombinant HiPIP-I from Ectothiorhodospira-halophila. Inorg. Chem. 1995, 34, 2516-2523.

(21) Bertini, I.; Donaire, A.; Felli, I. C.; Luchinat, C.; Rosato, A. H-1 and C-13 NMR studies of an oxidized HiPIP. Inorg. Chem. 1997, 36, 47984803.

(22) Breiter, D. R.; Meyer, T. E.; Rayment, I.; Holden, H. M. The molecular-structure of the High-Potential Iron-Sulfur protein isolated from Ectothiorhodospira-halophila determined at 2.5-A resolution. J. Biol. Chem. 1991, 266, 18660-18667.

(23) Bertini, I.; Campos, A. P.; Luchinat, C.; Teixeira, M. A Mossbauer investigation of oxidized Fe4S4 Hipip-II from Ectothiorohodospirahalophila. J. Inorg. Biochem. 1993, 52, 227-234.

(24) Bertini, I.; Eltis, L. D.; Felli, I. C.; Kastrau, D. H. W.; Luchinat, C.; Piccioli, M. The solution structure of oxidized HiPIPI from Ectothiorhodospira halophila; Can NMR spectroscopy be used to probe rearrangements associated with electron transfer processes? Chem. Eur. J. 1995, 1, 598-607.

(25) Krishnamoorthi, R.; Markley, J. L.; Cusanovich, M. A.; Przysiecki, C. T.; Meyer, T. E. Hydrogen-1 nuclear magnetic resonance investigation of high-potential iron-sulfur proteins from Ectothiorhodospira halophila and Ectothiorhodospira vacuolata: a comparative study of hyperfine-shifted resonances. Biochemistry 1986, 25, 60-67.

(26) Dilg, A. W.; Mincione, G.; Achterhold, K.; lakovleva, O.; Mentler, M.; Luchinat, C.; Bertini, I.; Parak, F. G. Simultaneous interpretation of Mossbauer, EPR and 57Fe ENDOR spectra of the [Fe4S4] cluster in the high-potential iron protein I from Ectothiorhodospira halophila. J. Biol. Inorg. Chem. 1999, 4, 727-741.

(27) Belinskiy, M.; Bertini, I.; Galas, O.; Luchinat, C. An exchange coupling model for the Fe4S43+ polymetallic center present in high potential iron-sulfur proteins. Inorg. Chim. Acta 1996, 243, 91-99.

(28) (a) Bertini, I.; Capozzi, F.; Luchinat, C.; Piccioli, M. 1H-NMR investigation of oxidized and reduced high-potential iron-sulfur protein from Rhodopseudomonas globiformis. Eur. J. Biochem. 1993, 212, 69-78; (b) Westler, W. M.; Lin, I. J.; Perczel, A.; Weinhold, F.; Markley, J. L. Hyperfine-shifted $13 \mathrm{C}$ resonance assignments in an iron-sulfur protein with quantum chemical verification: aliphatic CH...S 3-center-4-electron interactions. J. Am. Chem. Soc. 2011, 133, 1310-1316.

(29) Bertini, I.; Engelke, F.; Gonnelli, L.; Knott, B.; Luchinat, C.; Osen, D.; Ravera, E. On the use of ultracentrifugal devices for sedimented solute NMR. J. Biomol. NMR 2012, 54, 123-127.

(30) Griffiths, J. M.; Griffin, R. G. Nuclear magnetic resonance methods for measuring dipolar couplings in rotating solids. Anal. Chim. Acta 1993, 283, 1081-1101.

(31) Zhang, R.; Nishiyama, Y.; Sun, P.; Ramamoorthy, A. Phase cycling schemes for finite-pulse-RFDR MAS solid state NMR experiments. J. Magn. Reson. 2015, 252, 55-66. 
(32) (a) Holl, S. M.; Marshall, G. R.; Beusen, D. D.; Kociolek, K.; Redlinski, A. S.; Leplawy, M. T.; McKay, R. A.; Vega, S.; Schaefer, J. Determination of an 8-Angstrom interatomic distance in a helical peptide by solid-state NMR-spectroscopy. J. Am. Chem. Soc. 1992, 114, 4830-4833; (b) Saalwachter, K.; Graf, R.; Demco, D. E.; Spiess, H. W. Heteronuclear double-quantum MAS NMR spectroscopy in dipolar solids. J. Magn. Reson. 1999, 139, 287-301.

(33) Clement, R. J.; Pell, A. J.; Middlemiss, D. S.; Strobridge, F. C.; Miller, J. K.; Whittingham, M. S.; Emsley, L.; Grey, C. P.; Pintacuda, G. Spin-transfer pathways in paramagnetic lithium transition-metal phosphates from combined broadband isotropic solid-state MAS NMR spectroscopy and DFT calculations. J. Am. Chem. Soc. 2012, 134, 17178-85.

(34) Barbet-Massin, E.; Pell, A. J.; Retel, J. S.; Andreas, L. B.; Jaudzems, K.; Franks, W. T.; Nieuwkoop, A. J.; Hiller, M.; Higman, V.; Guerry, P.; Bertarello, A.; Knight, M. J.; Felletti, M.; Le Marchand, T.; Kotelovica, S.; Akopjana, I.; Tars, K.; Stoppini, M.; Bellotti, V.; Bolognesi, M.; Ricagno, S.; Chou, J. J.; Griffin, R. G.; Oschkinat, H.; Lesage, A.; Emsley, L.; Herrmann, T.; Pintacuda, G. Rapid proton-detected NMR assignment for proteins with fast magic angle spinning. J. Am. Chem. Soc. 2014, 136, 12489-12497.

(35) Marchetti, A.; Jehle, S.; Felletti, M.; Knight, M. J.; Wang, Y.; Xu, Z. Q.; Park, A. Y.; Otting, G.; Lesage, A.; Emsley, L.; Dixon, N. E.; Pintacuda, G. Backbone assignment of fully protonated solid proteins by $1 \mathrm{H}$ detection and ultrafast Magic-Angle-Spinning NMR Spectroscopy. Angew. Chem. Int. Ed. 2012, 51, 10756-10759.

(36) Capozzi, F.; Ciurli, S.; Luchinat, C. In Metal Sites in Proteins and Models Redox Centres; Hill, H. A. O., Sadler, P. J., Thomson, A. J., Ed.; Springer Berlin Heidelberg: Berlin, Heidelberg, 1998; pp 127-160.

(37) Banci, L.; Bertini, I.; Luchinat, C.; Pierattelli, R.; Shokhirev, N. V.; Walker, F. A. Analysis of the Temperature Dependence of the 1H and $13 \mathrm{C}$ Isotropic Shifts of Horse Heart Ferricytochrome c: Explanation of Curie and Anti-Curie Temperature Dependence and Nonlinear Pseudocontact Shifts in a Common Two-Level Framework. J. Am. Chem. Soc. 1998, 120, 8472-8479.

(38) Bertini, I.; Briganti, F.; Luchinat, C.; Scozzafava, A.; Sola, M. Proton NMR spectroscopy and the electronic structure of the high potential iron-sulfur protein from Chromatium vinosum. J. Am. Chem. Soc. 1991, 113, 1237-1245.

(39) (a) Andreas, L. B.; Jaudzems, K.; Stanek, J.; Lalli, D.; Bertarello, A.; Le Marchand, T.; Cala-De Paepe, D.; Kotelovica, S.; Akopjana, I.; Knott, B.; Wegner, S.; Engelke, F.; Lesage, A.; Emsley, L.; Tars, K.; Herrmann, T.; Pintacuda, G. Structure of fully protonated proteins by proton-detected magic-angle spinning NMR. Proc. Natl. Acad. Sci. USA 2016, 113, 9187-9192; (b) Stanek, J.; Andreas, L. B.; Jaudzems, K.; Cala, D.; Lalli, D.; Bertarello, A.; Schubeis, T.; Akopjana, I.; Kotelovica, S.; Tars, K.; Pica, A.; Leone, S.; Picone, D.; Xu, Z. Q.; Dixon, N. E.; Martinez, D.; Berbon, M.; El Mammeri, N.; Noubhani, A.; Saupe, S.; Habenstein, B.; Loquet, A.; Pintacuda, G. NMR Spectroscopic Assignment of Backbone and Side-Chain Protons in Fully Protonated Proteins: Microcrystals, Sedimented Assemblies, and Amyloid Fibrils. Angew. Chem. Int. Ed. 2016, 55, 1-6; (c) Zhang, R.; Mroue, K. H.; Ramamoorthy, A. Proton-Based Ultrafast Magic Angle Spinning Solid-State NMR Spectroscopy. Acc. Chem. Res. 2017, 50, 1105-1113.

(40) Pell, A. J.; Pintacuda, G. Broadband solid-state MAS NMR of paramagnetic systems. Prog. Nucl. Magn. Reson. Spectrosc. 2015, 8485, 33-72. 